\title{
Reorganization of the Primary Motor Cortex of Adult Macaque Monkeys after Sensory Loss Resulting from Partial Spinal Cord Injuries
}

\author{
Niranjan Kambi, Shashank Tandon, Hisham Mohammed, Leslee Lazar, and Neeraj Jain \\ National Brain Research Centre, Manesar, Haryana 122 050, India
}

Long-term injuries to the dorsal columns of the spinal cord at cervical levels result in large-scale somatotopic reorganization of the somatosensory areas of the cortex and the ventroposterior nucleus of the thalamus. As a result of this reorganization, intact inputs from the face expand into the deafferented hand representations. Dorsal column injuries also result in permanent deficits in the use of digits for precision grip and a loss of fractionated movements of the digits. We determined whether the chronic loss of sensory inputs and the behavioral deficits caused by lesions of the dorsal columns in adult macaque monkeys affect organization of the motor cortex. The results show that, in the primary motor cortex, intracortical microstimulation evokes extension-flexion movements of the thumb at significantly fewer sites compared with the normal monkeys. There is a corresponding increase in the adduction-abduction movements. Furthermore, there is a significant increase in the thresholds of the currents required to evoke movements of the digits. Thus, long-term sensory loss in adult monkeys does not change the overall topography of the movement representation in the motor cortex but results in changes in the details of movement representations.

\section{Introduction}

Sensory inputs play an important role in shaping motor output. Sherrington observed motor deficiencies after sensory loss in macaque monkeys with dorsal root transections (Mott and Sherrington, 1895). Many studies have since shown that motor behavior in both humans and nonhuman primates is affected by sensory deprivation resulting from dorsal root or dorsal column transections, skin anesthesia, peripheral neuropathy, or inactivation of the somatosensory cortex (Nathan and Sears, 1960; Rothwell et al., 1982; Vierck, 1982; Sanes et al., 1984; Hikosaka et al., 1985; Gentilucci et al., 1997; Brochier et al., 1999; Darian-Smith and Ciferri, 2005). Loss of sensory inputs also affects learning of new motor skills (Pavlides et al., 1993).

To execute movements precisely, sensory inputs to the motor cortex must be in register with the motor control circuits to provide accurate feedback (Sanes and Donoghue, 1992; Osborne et al., 2005). However, chronic sensory loss resulting from lesions of the dorsal columns of the spinal cord causes large-scale reorganization of the somatosensory area $3 \mathrm{~b}$, the secondary somatosensory area, the parietal ventral area, and the ventroposterior nucleus of the thalamus (Jain et al., 1997, 2000, 2008; Tandon et

Received Sept. 22, 2010; revised Dec. 24, 2010; accepted Jan. 18, 2011.

This work was supported by Wellcome Trust International Senior Research Fellowship Grant 063259/Z/00/Z (N.J.). N.J. also acknowledges full salary support from the Trust for 5 years. Part of this work was also funded by core funds from National Brain Research Centre. N.K. and H.M. were Research Fellows of the Council of Scientific and Industrial Research. We thank Dr. Rema Velayudhan for helpful comments on this manuscript, Radhika Rajan for help with mapping experiments, Dr. Elizabeth Thomas for help with the statistical methods, and Mithlesh and Hari Shankar for histological assistance.

Correspondence should be addressed to Neeraj Jain, National Brain Research Centre, NH-8, Manesar, Haryana 122 050, India. E-mail: neeraj.jain@nbrc.ac.in or njain.nbrc@gmail.com.

DOI:10.1523/JNEUROSCI.5187-10.2011

Copyright $\odot 2011$ the authors $\quad 0270-6474 / 11 / 313696-12 \$ 15.00 / 0$ al., 2009). As a result of this reorganization, neurons in the deafferented parts of the hand representations in these areas acquire receptive fields on the face, which would result in abnormal inputs to part of the motor cortex that controls hand movements, possibly affecting its organization.

Lesions of the dorsal columns also result in permanent behavioral deficits in the use of the digits for making precision grips and fractionated movements of the digits (Farrera and Barrera, 1934; Gilman and Denny-Brown, 1966; Glendinning et al., 1992; Cooper et al., 1993). Since the motor cortex gets reorganized by changes in the normal patterns of movement execution (Nudo et al., 1996; Kleim et al., 1998; Pearce et al., 2000; Tyc et al., 2005), the altered behavioral use of the digits after dorsal column lesions can also affect the organization of the motor cortex.

In the previous studies on the effects of sensory loss on the motor cortex (Mott and Sherrington, 1895; Sherrington, 1931; Asanuma and Arissian, 1984), a detailed analysis of the movement map was not done. Here, we used three adult macaque monkeys with chronic unilateral lesions of the dorsal columns to make detailed movement maps of the motor cortex. The motor cortex was mapped after a recovery period of 9 months or more, using standard intracortical microstimulation (ICMS) methods. In the same monkeys, the extent of reorganization of somatosensory area $3 \mathrm{~b}$ was determined for a direct comparison.

\section{Materials and Methods}

Animals. Three adult macaque monkeys (Macaca mulatta), two males (LM78 and LM98) and one female (LM01), received unilateral lesions of the dorsal columns. The monkeys weighed between 7.34 and $10.54 \mathrm{~kg}$ at the time of the lesion. Both the motor cortex and the somatosensory cortex were mapped in these monkeys. In addition, the motor cortex was mapped in one normal adult male monkey (Macaca mulatta; NM56; 7.34 
$\mathrm{kg})$. The animal protocols were approved by the Animal Ethics Committee of the National Brain Research Centre, and the Committee for the Purpose of Control and Supervision of Experiments on Animals, Government of India.

Dorsal column lesions. The monkeys were anesthetized using a mixture of ketamine $(8 \mathrm{mg} / \mathrm{kg}$, i.m.) and xylazine $(0.4 \mathrm{mg} / \mathrm{kg}$, i.m. $)$ with supplemental doses given as required, at one-tenth of the initial dose. The surgical site was prepared, a midline incision was made over the dorsal spinal cord, and the muscles were retracted. After partial laminectomy, the dura was incised and retracted, and the dorsal columns were lesioned on one side using a pair of sharp fine forceps (Jain et al., 2008; Tandon et al., 2009). The lesion was made taking care to minimize damage to the surface blood vessels. After making the lesion, the dura was folded back in place and the spinal cord was covered with Gelfoam. The muscles and the skin were sutured in layers. The animals were given antibiotics, analgesics, and dexamethasone (in reducing dose) for $5 \mathrm{~d}$ after surgery (Jain et al., 2008). During the recovery period, the animals were carefully monitored for food and fluid intake, and signs of self-injury. No complications were observed and the recoveries were uneventful.

ICMS of the motor cortex. Organization of the motor cortex was determined by stimulating with microelectrodes at a dense array of stimulation sites after a recovery period of 9 months or more after the lesion.

For ICMS, the animals were anesthetized with ketamine and xylazine as described above. Uniform anesthesia level was maintained by giving additional supplemental doses of urethane $(250 \mathrm{mg} / \mathrm{kg}$, i.p. $)$ at $\sim 6-8 \mathrm{~h}$ intervals. The animals were given continuous intravenous infusion of normal saline $\left(7 \mathrm{ml} \cdot \mathrm{kg}^{-1} \cdot \mathrm{h}^{-1}\right)$. After every $8 \mathrm{~h}$, the intravenous fluids were supplemented with dextrose $(2.5 \%$ in saline) for $4 \mathrm{~h}$. The brain was exposed in the region of interest, and neurons in the motor cortex were stimulated using parylene-coated tungsten microelectrodes $(1 \mathrm{M} \Omega$ at 1 $\mathrm{kHz}$; Microprobe) using a constant current stimulator (model S88; Grass Technologies). Stimulation in the anterior bank of the central sulcus was done at $400 \mu \mathrm{m}$ intervals beginning at $1500 \mu \mathrm{m}$ below the brain surface (see Fig. 1). The electrode was advanced using an electronically controlled hydraulic microdrive (David Kopf Instruments). The goal was to place the tip of the electrode in layer 5 of the cortex. In case the electrode location was not optimum as judged by the lack of evoked movements at several successive depths, multiple penetrations were made at different rostrocaudal distances from the central sulcus. For stimulation of the rostrally adjacent cortex on the surface of the brain, the electrode was advanced to a depth of $1500 \mu \mathrm{m}$, the approximate location of the top of layer 5. Neurons at each site were stimulated by $60 \mathrm{~ms}$ trains of $0.2 \mathrm{~ms}$ cathodal pulses at $150 \mathrm{~Hz}$ (Tandon et al., 2008; Qi et al., 2010). The bursts of trains were separated by $\sim 1 \mathrm{~s}$ intervals. Locations of the electrode penetration sites were marked on an enlarged picture of the cortical surface using surface vasculature pattern as a reference. Initially, $50 \mu \mathrm{A}$ current was used to determine whether any movement was evoked. If a movement was visible, the current was progressively decreased to determine the threshold current. Threshold current was defined as the minimum current at which a visible movement of any body part was reliably evoked, as confirmed by two observers. If no movement was observed initially at $50 \mu \mathrm{A}$, the current was slowly increased until a definite movement was observed. The threshold current was then determined by decreasing the current. The maximum current used was $100 \mu \mathrm{A}$ to avoid electrolytic damage to the cortex (Asanuma and Arnold, 1975). Care was taken to keep the muscles in a relaxed state by manually moving the limbs and muscles during gaps between the stimulation cycles (Tandon et al., 2008). Body parts were kept in the same position between stimulations for all the monkeys.

At the end of the mapping procedure, small electrolytic lesions were made at selected locations to help in identification of the electrode penetration sites in the histological sections of the cortex (see below). To determine the trajectory of the electrode, lesions were made along a few tracks by continuously passing $10 \mu \mathrm{A}$ current as the electrode was withdrawn at the rate of $25 \mu \mathrm{m} / \mathrm{s}$ (see Fig. $1 B$ ).

Microelectrode mapping of the somatosensory cortex. Standard multiunit mapping procedures (Jain et al., 2008) were used to map the primary somatosensory cortex ( $\mathrm{S} 1$ or area $3 \mathrm{~b}$ ) and the surrounding cortex (see Fig. 1). Neuronal activity was recorded using parylene-coated tungsten microelectrodes ( $1 \mathrm{M} \Omega$ at $1 \mathrm{kHz}$; Microprobe), and the receptive fields of neurons were determined at a large number of recording sites. Area $3 \mathrm{~b}$ was mapped by inserting the electrode perpendicular to the exposed cortical surface. The receptive fields were determined at $300-400 \mu \mathrm{m}$ intervals as the electrode was advanced down the cortex of the posterior bank of the central sulcus. At each recording site, the entire body was thoroughly explored for neuronal responses to cutaneous stimulation, taps, and movements of joints and muscles. If many nonresponsive sites were encountered in a penetration, additional closely spaced penetrations were made at different rostrocaudal distances from the central sulcus to fully explore the cortex folded in the posterior bank of the central sulcus. Small electrolytic lesions were made toward the end of the mapping procedure as described above. For other details of the mapping procedures, see Tandon et al. (2009). For each monkey, the complete mapping sessions lasted between 3 and $5 \mathrm{~d}$.

Histology. After completion of the mapping procedures, the monkeys were perfused transcardially with sodium phosphate buffer containing $0.9 \% \mathrm{NaCl}(0.1 \mathrm{M}), \mathrm{pH} 7.5$, followed by buffered 3\% paraformaldehyde (0.1 M phosphate buffer, $\mathrm{pH} 7.5$ ), and finally by paraformaldehyde containing $10 \%$ sucrose. The brain was removed, and the cortex was separated from the underlying tissue, blocked, and cryoprotected in 30\% sucrose. A block of the cortex surrounding the central sulcus was frozen and cut into $50-\mu \mathrm{m}$-thick sections on a sliding microtome in a plane perpendicular to the central sulcus, which is slightly off the parasagittal plane. For monkey LM01, the cortex was cut in the coronal plane. Different series of sections from the cortex were stained for Nissl substance, myelin (Jain et al., 1998), cytochrome oxidase (CO) activity (WongRiley, 1979), acetylcholine esterase (AChE) activity (Geneser-Jensen and Blackstad, 1971), and SMI32 antibody (Covance) (Preuss et al., 1997) to help identify electrode tracks and to determine architectonic boundaries between different cortical areas (see Fig. 1C) (Preuss et al., 1997).

The spinal cord was also carefully removed, cryoprotected as above, and cut in a horizontal plane at a thickness of $40 \mu \mathrm{m}$. The sections were mounted unstained for reconstruction of the lesion site (for details, see Tandon et al., 2009).

Reconstruction of the topographic maps. For reconstruction of the motor maps, threshold currents required to evoke movements were divided into five groups, $1-20,21-40,41-60,61-80,81-100 \mu \mathrm{A}$, and marked at the stimulation sites with differently sized markers. Borders between the markers were placed to demarcate regions evoking movements of different body parts. The borders were drawn (1) midway between the adjacent sites evoking movements of different body parts, (2) through the sites where movements of two different body parts were evoked at the threshold current, and (3) midway between a responsive and an unresponsive site (Tandon et al., 2008). As far as possible, sites evoking movements of the same body part were placed into one or minimum number of contiguous zones. For locations where multiple deep penetrations were made at different distances from the central sulcus, the penetration points were merged such that the lowest threshold current required to evoke the movement was plotted.

To precisely find the locations of the stimulation sites in the brain, sections of the cortex stained for Nissl substance were drawn using a microscope equipped with camera lucida. Location of layer 5 was marked on the drawings of the sections. The architectonic boundaries of different motor areas in the anterior bank of the central sulcus and the adjoining motor cortex on the dorsal surface were identified and drawn using the sections stained for Nissl substance, SMI-32 antibody, and AChE and CO activity. Locations and the angles of the electrode tracks were marked with the help of the electrolytic lesions made during the mapping sessions. Finally, a pseudo-three-dimensional reconstruction of the motor cortex was done to represent topography in the anterior bank of the central sulcus, and the rostrally adjacent dorsal surface of the frontal lobe.

Somatosensory map was also reconstructed using essentially the same procedures. For details regarding reconstruction of the somatosensory maps, see Tandon et al. (2008).

Reconstruction of the spinal cord lesion. Drawings of the spinal cord sections in the region of the lesion were made using a microscope equipped with camera lucida. The maximal extent of the lesion and the boundaries of the white matter and the gray matter were measured from 
these drawings. A view of the spinal cord in the coronal plane in the region of the lesion was reconstructed using these measurements to delineate the extent of the lesion (for details, see Tandon et al., 2008).

Statistical analysis. For determining statistical significance of the quantitative data, each lesioned monkey was compared with the normal monkey. We also compared our normal monkey, NM56, with data obtained from the published map of the motor cortex of a normal monkey [Qi et al. (2000), their Fig. 2A]. We did not find any significant difference between NM56 and the normal monkey of Qi et al. (2000) for any of the quantitative parameters, except for the absolute current thresholds for some of the movements.

The area of representation for the digits, wrist, and shoulder in monkey mapped by Qi et al., was 51.6, 33.0, and $15.4 \%$ of the total area of representation of these regions. There is no significant difference between these values and those for our normal monkey ( $p=0.750$, Wilcoxon's test). Between our monkey and the monkey of Qi et al., the nature of evoked movements (extension-flexion vs adduction-abduction) was also not significantly different for either D1 (extension-flexion at 26 sites and adduction-abduction at 1 site; $p=1.000$, Fisher's exact test), or D2 (extension-flexion at 34 sites and adduction-abduction at 4 sites; $p=$ 0.519). Similarly, the number of sites where movements evoked were only of D1, or of D1 along with other digits, were also not significantly different $(p=0.282)$.

The mean threshold currents reported by Qi et al. were 25.35, 34.74, 38 , and $25 \mu \mathrm{A}$ for movements of the digits, wrist, elbow, and shoulder movements, respectively. The differences in threshold currents between the two studies are likely because the threshold currents are more sensitive to experimental conditions including type of anesthetic, level of anesthesia, and the state of the animal (Nudo et al., 1996), and therefore most likely to vary between different laboratories. However, other parameters, such as the frequencies and nature of movements are less likely to be affected by these conditions. For additional details of statistical analysis, and data for monkey from this study, please see Results.

\section{Results}

We mapped motor cortex in three monkeys with lesions of the dorsal columns and one normal monkey. In the monkeys with lesions, the somatosensory area $3 \mathrm{~b}$ was also mapped for comparison. We first describe our results on the topographic organization of the motor cortex in the normal monkey, and the monkeys with lesions of the dorsal columns. We then present our data on details of the nature of movements evoked and the threshold currents required to evoke the movements.

\section{Normal organization of the motor cortex in monkey NM56}

We could delineate the rostral border of primary motor cortex (M1) from the brain sections stained for SMI32 immunohistochemistry (Fig. 1C) (Preuss et al., 1997; Geyer et al., 2000). M1 has been often subdivided into two parts, the caudal subdivision, located in the rostral bank of the central sulcus, and the rostral subdivision, located on the rostrally adjacent dorsal surface of the brain (Strick and Preston, 1978; Stepniewska et al., 1993; Preuss et al., 1997; Rathelot and Strick, 2006, 2009). We mapped both these regions of $\mathrm{M} 1$ and parts of the premotor cortex. In the rostral bank of the central sulcus, neurons were stimulated at 241 sites, and on the dorsal surface of the precentral gyrus 107 sites were stimulated.

In the M1, the regions evoking movements of different body parts were organized in a mediolateral strip. The movements of the face and the oral cavity structures were evoked in the lateral M1, and the movements of the forelimb (digits, wrist, and elbow), shoulder, and trunk were evoked from progressively more medial sites (Fig. 2). This topographic arrangement is similar to what has been reported previously.

Among the representations of different parts of the forelimb, the digit representation was the largest and lateralmost. The wrist
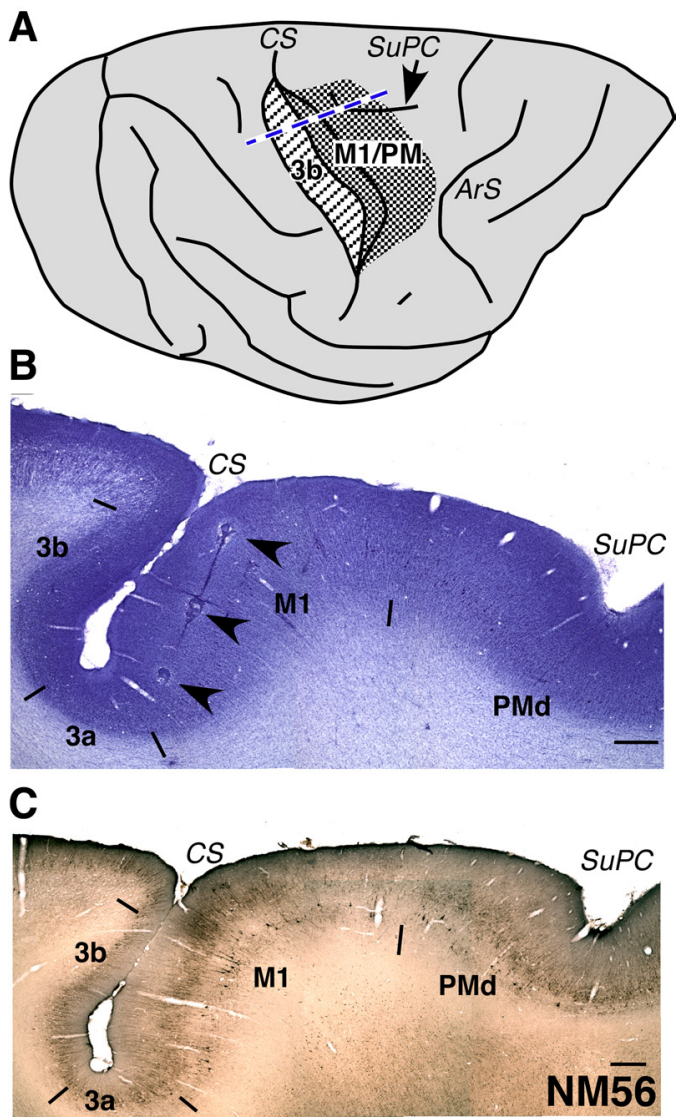

Figure 1. A, A drawing of the dorsolateral view of a macaque monkey brain showing portions of the motor cortex (dense stippling) and the somatosensory area $3 \mathrm{~b}$ (striped stippling) that were mapped. The densely stippled area included parts of both M1 and the premotor cortex (PM). The central sulcus has been opened for visualization in its depth. The blue dashed line shows the approximate location from where the sections shown in $\boldsymbol{B}$ and $\boldsymbol{C}$ were taken. ArS, Arcuate sulcus; CS, central sulcus; SuPC, superior precentral dimple. The rostral is to the right, and medial is to the top. $\boldsymbol{B}$, A section of the brain from the normal monkey, NM56 stained for Nissl substance. The section was taken from the approximate location shown by the dashed line in $\boldsymbol{A}$. The brain was cut in a plane perpendicular to the central sulcus (see Materials and Methods). An electrode track marked by electrolytic lesions is clearly visible (arrowheads). Borders of the somatosensory areas 3b, 3a, M1, and PMd are marked by short lines. The borders were determined by visualization in adjacent sections stained for Nissl, SMI-32 immunostaining (see C), acetylcholine esterase activity, and cytochrome oxidase activity. C, A section of the brain through the central sulcus stained by SMI-32 immunohistochemistry. The border between M1 and PMd is visible in such sections. In $\boldsymbol{B}$ and $\boldsymbol{C}$, rostral is to the right. Scale bar, $1 \mathrm{~mm}$.

representation was medial to the digit representation, followed by representation of the elbow movements further medially. However, a few stimulation sites with wrist and elbow movements were also present within the digit region. Wrist and elbow movements were also evoked from few sites in the shoulder region. The maximal mediolateral extent of contiguous digit representation was $7.3 \mathrm{~mm}$. The medial boundaries of the wrist and elbow representations were 7.8 and $8.5 \mathrm{~mm}$ from the hand-face border. Such an organization of the motor cortex is similar to what has been reported previously from ICMS and anatomical studies (Kwan et al., 1978; Sessle and Wiesendanger, 1982; Qi et al., 2000; Park et al., 2001; Rathelot and Strick, 2009).

The overall topography in part of M1 on the rostrally adjacent dorsal surface of the brain was similar to that seen for caudal M1. However, the area of the digit representation was relatively smaller and that of the wrist representation was larger. Further rostrally, between the precentral dimple and the genu of the arcuate sulcus, in the area that corresponds to dorsal premotor area 


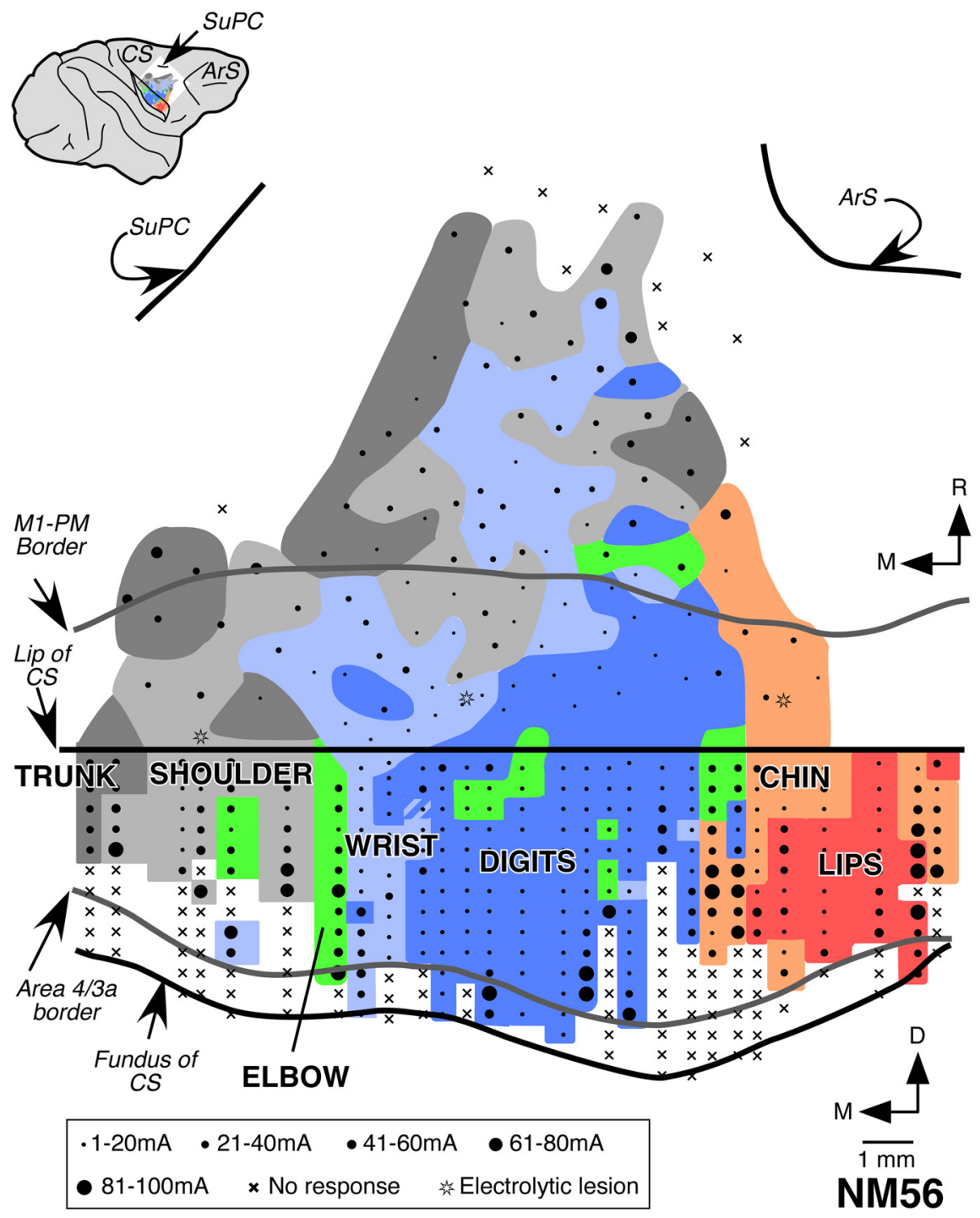

Figure 2. Organization of the motor cortex in normal macaque monkey, NM56. This view shows the rostral bank of the central sulcus and the rostrally adjacent dorsal surface of the frontal lobe. Rostral lip of the central sulcus is marked by the horizontal straight line. Regions from which movements of different body parts were evoked at threshold currents are color coded as labeled. Striped regions mark the regions where movements of two body parts were evoked as per the color code. The stimulation sites are marked by dots or crosses. The dot size indicates the threshold current range as shown in the key at the bottom, crosses mark the sites where no movement was evoked, and stars mark the penetrations where electrolytic lesions were made. Border between area 3a and 4, and M1 and premotor cortex (PM) are shown (gray lines) (Fig. 1). The inset on top left is a drawing of the lateral view of the brain showing location of the area mapped. D, Dorsal; M, medial; R, rostral. Other abbreviations are as in Figure 1.

(PMd) or F2 (Geyer et al., 2000), representations of the movements of the wrist, shoulder, and trunk were more predominant, as expected. Here, the wrist representation was surrounded by regions where shoulder and trunk movements were evoked (Sessle and Wiesendanger, 1982; Godschalk et al., 1995; Park et al., 2001; Raos et al., 2003).

\section{Organization of the motor and the somatosensory cortex in the lesioned monkeys}

Monkey LM98

In this monkey, the dorsal columns were transected on the left side at C4/C5 spinal level. The lesion was partial with sparing of the dorsal columns in the medial-dorsal location (Fig. 3D). The spared fibers mostly correspond to the location of the fasciculus gracilis. This was ascertained by extending the clearly visible posterior intermediate septum, the border between the fasciculus gracilis and the fasciculus cuneatus, in the sections of the spinal cord, rostral and caudal to the lesion site (Fig. 3E). The damage extended to the ventralmost fibers in the left dorsal columns, the right dorsal horn, and the medial parts of the gray matter on both the sides. This monkey was mapped 10.5 months after the lesion was made.

To determine the organization of the movement map in this monkey, we made 60 electrode penetrations and stimulated neurons at a total of 401 sites in the rostral bank of the central sulcus and the rostrally adjacent cortex on the dorsal surface of the brain. The organization of the caudal M1 in this monkey revealed representations of the movements of the lips, chin, digits, wrist, elbow, and shoulder in a lateral to medial order (Fig. $3 B$ ). The elbow and the wrist movements were evoked predominantly at sites that were medial to the digit representation, and at a few locations within the digit and shoulder representations. The total mediolateral extent of the digit representation was 10.8 $\mathrm{mm}$. The medialmost points from which the wrist and the elbow movements were evoked were 10.7 and $13.1 \mathrm{~mm}$ from the hand-face border, respectively. Thus, the overall topography and the extent of representations of different parts of the forelimb were as in the normal monkey (compare Fig. 2).

The organization of part of the M1 on the surface of the precentral frontal lobe was also normal. The digit representation was smaller than in the caudal M1, whereas the movements of the wrist were evoked from a relatively larger region. Area PMd was not extensively mapped in this monkey except for the caudalmost region, where the topography was as for the normal monkey.

We mapped the somatosensory area $3 \mathrm{~b}$ to determine the extent of its reorganization for comparison with the motor cortex and with the previous reports. A total of 18 penetrations were made in the caudal bank of the central sulcus, where receptive fields at 241 recording sites were mapped. The results show that, in the entire deafferented parts of area $3 \mathrm{~b}$, where representations of the hand and arm are normally expected, neurons responded to stimulation on the chin (Fig. 3C). We did not observe any response to touch on the hand except for one recording site where neurons had dual receptive field on the chin and D1. The chin inputs had expanded as far as the medialmost recorded site, which was $7.4 \mathrm{~mm}$ from the expected location of the prelesion hand-face border, near the lateral end of the intraparietal sulcus (Jain et al., 1998).

\section{Monkey LM78}

In monkey LM78, the dorsal column lesion was on the left side at C4/C5 spinal level. The lesion (Fig. 4C) was nearly complete with sparing of the dorsalmost fibers along the midline, mostly corresponding to the location of the fasciculus gracilis (Fig. 4D). Ipsilateral dorsal horn, medial gray matter on both sides, and parts of 


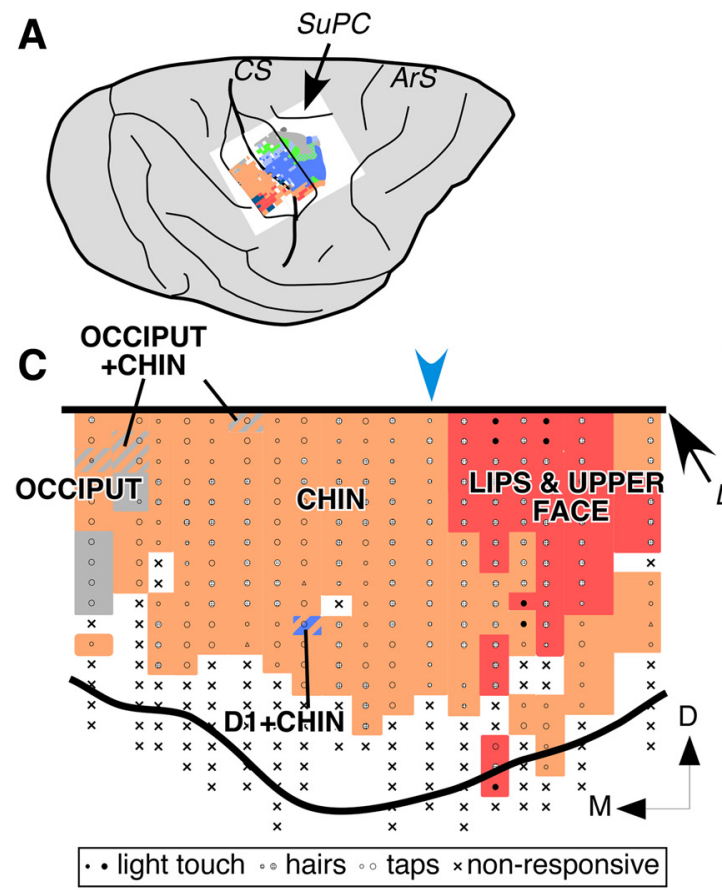

D

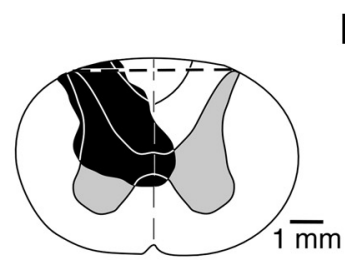

$\mathbf{E}$

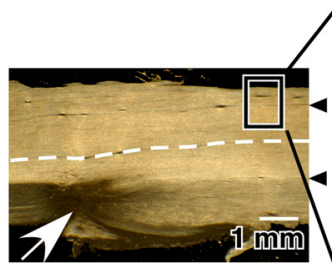

B

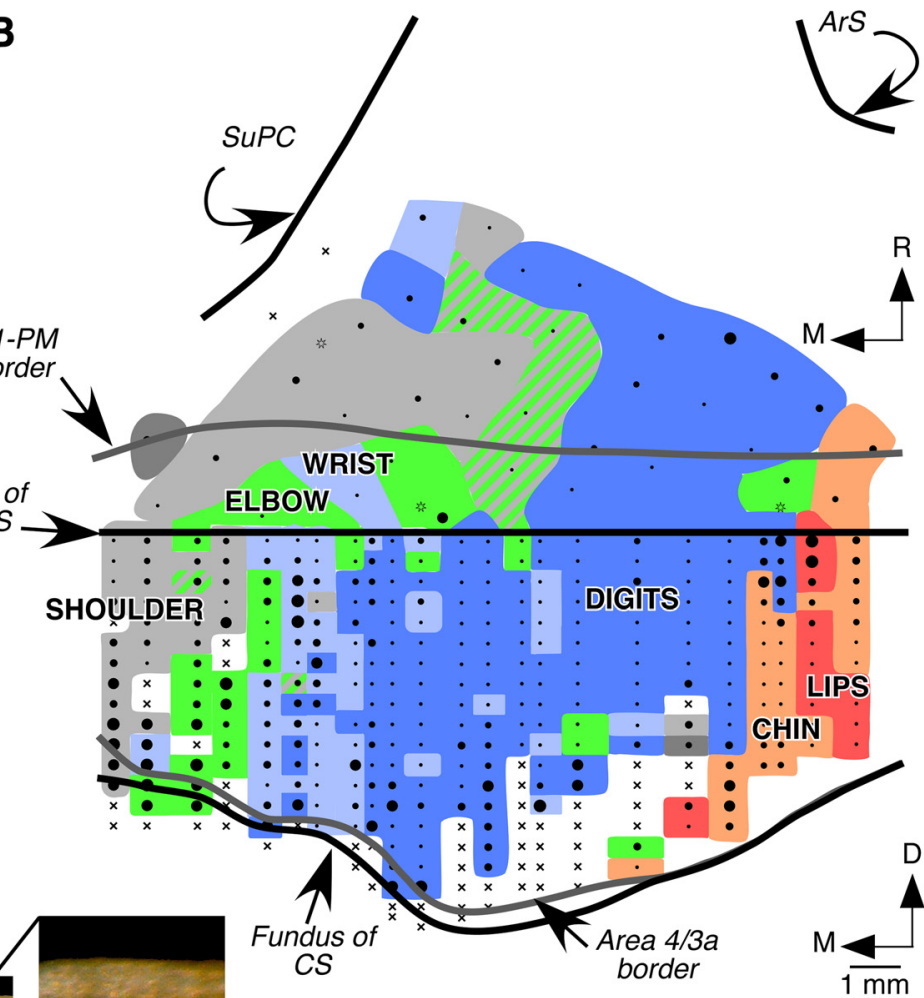

$\cdot 1-20 \mathrm{~mA} \cdot 21-40 \mathrm{~mA} \cdot 41-60 \mathrm{~mA} \cdot 61-80 \mathrm{~mA}$

$\bullet 81-100 \mathrm{~mA} \times$ No response

LM98

Figure 3. Organization of the motor and somatosensory cortex in monkey LM98 with lesion of the dorsal columns on the left side. $A$, A lateral view of the brain with opened central sulcus showing the mapped portions of the motor and somatosensory areas. B, Organization of the motor cortex in a view similar to that shown in Figure 2 . Note that the topography of the movement map is similar to that for the normal monkey, NM56 (compare Fig. 2). C, Somatotopy in area 3b of monkey LM98 showing expansion of the chin inputs (pink) into the deafferented hand region. The locations of the receptive fields are color coded as labeled. The striped regions indicate dual receptive fields on the body parts as per the color of the stripes. Responses to the stimulation of the hand were seen at only one recording site (blue and pink stripes), where responses to stimulation on the chin were also observed. The estimated location of the prelesion hand-face border is marked by the blue arrowhead (see Results). The nature of the receptive fields and the stimulus applied at each recording site is marked by a symbol shown in the key below the map. Smaller symbols indicate weak response and larger symbols an excellent response to the stimulation; crosses mark the locations were no neuronal responses were observed. $\boldsymbol{D}$, Reconstruction of the spinal cord in a coronal plane in the region of the lesion, which was made in the left side. The extent of the damage is marked in black. The gray matter through the lesion is shown for reference as a mirror image of the right side. The dashed line marks the location from which the section shown in $\boldsymbol{E}$ was taken. $\boldsymbol{E}$, A dark-field photomicrograph of a horizontal section of the spinal cord showing the lesion site (arrow). Rostral is to the left of the figure, and the left side of the spinal cord is toward the bottom. The arrowheads mark the posterior intermediate septa separating the cuneate and the gracile fasciculus. The box demarcates the region of the section that is shown enlarged on the right to show the septum more clearly. The white dashed line marks the midline. For abbreviations, see legends to Figures 1 and 2.

the ventral horns on both the sides were also damaged. In addition, the ventralmost parts of the dorsal columns on the right side were also damaged. There was also damage to the medial parts of the dorsolateral white matter.

The contralesional right motor cortex in this monkey was mapped 8.5 months after the lesion was made. We made 77 penetrations in the motor cortex and stimulated 417 sites. The overall topography of the movement representation in the motor cortex of this monkey was normal, with representation of the tongue and the face lateralmost, followed by representation of the forelimb (digits, wrist, and elbow), shoulder, trunk, and knee joint at progressively more medial locations (Fig. 4A). As for monkeys NM56 and LM98, the majority of the sites, where movements of the wrist and elbow were evoked, were medial to the digit representation. However, at a few sites, within the digit representation, stimulation evoked movements of the wrist and elbow. At one site near the hand-face border, movements of the shoulder were observed. Finally, few stimulation sites where wrist and elbow movements were evoked were in the shoulder representation.
The overall mediolateral extent of the digit representation in this monkey was $6.9 \mathrm{~mm}$, although most of the representation was within $4 \mathrm{~mm}$ from the hand-face border. The medialmost points where wrist and elbow movements were observed were 7.6 and $9 \mathrm{~mm}$, respectively, from the hand-face border. At many sites, particularly in the ventral part of the anterior bank of the central sulcus, stimulation failed to evoke any visible movement. Such nonresponsive points are often observed in experiments involving stimulation in the depths of sulci.

In the rostral part of M1, the lateral to medial sequence of the representation of movements of different body parts was similar to that seen for part of the M1 buried in the central sulcus. The digit representation was, however, smaller. These features of organization of the motor cortex are similar to those seen in normal monkeys.

We also mapped the somatosensory area $3 \mathrm{~b}$ in the right contralesional hemisphere of this monkey. A total of 22 electrode penetrations was made in the caudal bank of the central sulcus, and receptive fields were mapped at 219 recording sites. Somatotopy of area $3 \mathrm{~b}$ revealed extensive reorganization (Fig. $4 B$ ). Chin 

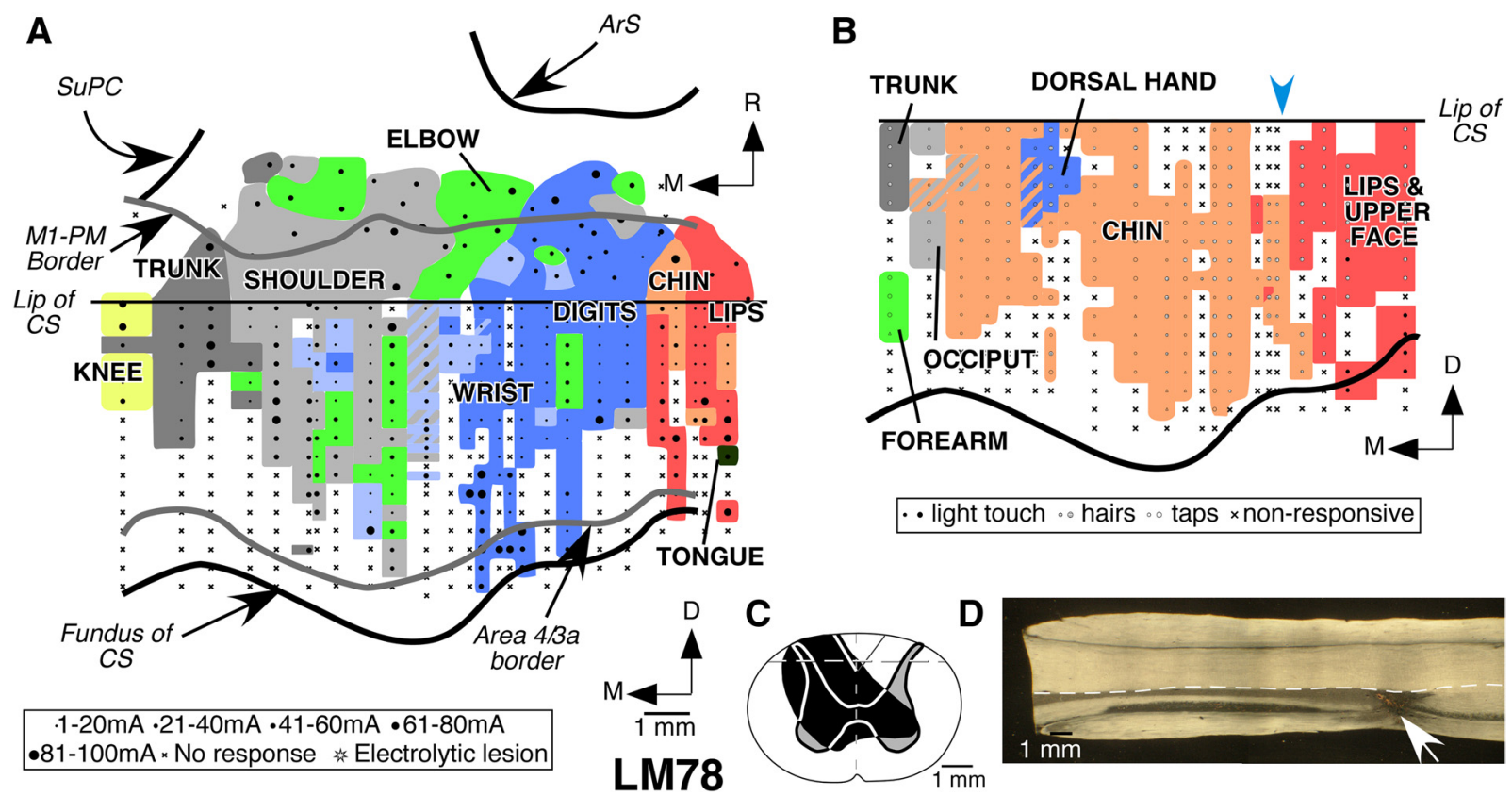

Figure 4. Organization of the motor and somatosensory cortex in monkey LM78 with lesion of the dorsal columns on the left side. $A$, Organization of the motor cortex in a view similar to that shown in Figure 2. Note that the topography of the movement map is normal-like (compare Fig. 2). The ventralmost part of the motor cortex was partially mapped in this monkey (see Results). $\boldsymbol{B}$, Somatotopy in area $3 \mathrm{~b}$ of monkey LM78. The chin inputs (pink) expand medially into the deafferented hand area. Responses to touch on the hand were seen only at a few recording sites (blue). The estimated location of the prelesion hand-face border is marked by the blue arrowhead (see Results). For other conventions, see legend to Figure 3. C, Reconstruction of the spinal cord in a coronal plane in the region of the lesion, which was made on the left side. The extent of the damage is marked in black. The gray matter through the lesion and the border between the fasciculus cuneatus and fasciculus gracilis is shown for reference as mirror image of the right side. The dashed line marks the location from which the section shown in $\boldsymbol{D}$ was taken. $\boldsymbol{D}$, A dark-field photomicrograph of a horizontal section of the spinal cord showing the lesion site (arrow). Rostral is to the left of the figure, and the left side of the spinal cord is toward the bottom. For abbreviations, see legends to Figures 1 and 2 .

inputs activated neurons as far medial as the representation of the shoulder. Responses to touch on the hand were found only at a few recording sites. Of these, four sites had dual receptive fields on both the hand and the face. Responses to touch on the forearm were seen at 12 recording sites medial to the expanded chin representation. These inputs enter the spinal cord rostral to the site of the lesion (Florence et al., 1988, 1989; Jain et al., 2008). At the medialmost recording sites, the receptive fields were on both the shoulder and the trunk. In this monkey, the chin representation had expanded by $8.2 \mathrm{~mm}$ from the expected location of the prelesion hand-face border. There were also few locations where neurons did not respond to any stimulation. Such nonresponsive points were likely because of less than optimal location of the electrode tip in the gray matter.

\section{Monkey LM01}

This monkey had dorsal column lesion on the left side at the C4 level. The lesion was partial with considerable sparing of the dorsal columns on the lateral side and a minor sparing medioventrally (Fig. $5 B$ ). The dorsal parts of the ventral horn and the intermediate gray matter were also damaged.

To determine the organization of the motor cortex in this monkey, we made 17 electrode penetrations and stimulated a total of 344 sites in the anterior bank of the central sulcus. The lateral to medial order of the representation of different body parts in the motor cortex of this monkey was normal (Fig. 5A). At the lateralmost stimulation sites, movements of the tongue were evoked; movements of the lips, chin, digits, wrist, elbow, and shoulder were seen at progressively more medial sites. Adjacent to the face region, there were few sites where ICMS evoked movements of the wrist and shoulder. Laterally, the representations of the wrist, elbow, and shoulder were partly intermixed, as for the other normal and lesioned monkeys. In this monkey, the digit representations was $4.9 \mathrm{~mm}$ in its mediolateral extent. The wrist movements and the elbow movements were observed up to 8.9 and $10.3 \mathrm{~mm}$, respectively, from the hand-face border. The topography in the caudal part of M1 was thus normal. The motor cortex on the dorsal surface of the precentral gyrus was not mapped in this monkey.

As for the other lesioned monkeys, we mapped area $3 \mathrm{~b}$ of this monkey. Here, we briefly describe the somatotopy in area $3 \mathrm{~b}$, because these data have been presented in detail previously (Tandon et al., 2009). In area $3 \mathrm{~b}$ of this monkey, neurons responded to the stimulation on the skin of the hand, which is consistent with the sparing of the dorsal column fibers. However, there was also large-scale expansion of the chin representation into the partially deafferented hand region [Tandon et al. (2008), their Fig. 5A], as has been previously reported for monkeys with partial lesions (Jain et al., 1997, 1998, 2008). The overall chin expansion in this monkey was $7.4 \mathrm{~mm}$ from the hand-face border, which was almost as far as the representation of the forearm.

Thus, in all the three monkeys with lesions of the dorsal columns, although the somatosensory cortex showed large-scale reorganization, the overall topography of the motor cortex remained normal.

\section{Areas of representations of the digits, wrist, and elbow}

Lesions of the dorsal columns of the spinal cord affect the distal limb movements more than the proximal movements (Farrera and Barrera, 1934; Vierck, 1978, 1982; Glendinning et al., 1992; Leonard et al., 1992). Therefore, we determined whether in monkeys with such lesions the extents of representations of the digits, wrist, and elbow are differently affected. We considered only that 
part of the motor cortex that is buried in the anterior bank of the central sulcus for this analysis, because the rostral part, which has a smaller digit representation, was mapped to varying extent in different monkeys.

For the normal monkey, NM56, and the three lesioned monkeys, LM98, LM78, and LM01, the percentage of the forelimb area where movements of the digit, wrist, and elbow were evoked is shown in Figure 6. As is obvious in Figures 2-6, the area of representation of the digits is largest among these three representations. In the normal monkey, the digits, wrist, and elbow representations occupied 65.1, 15.8, and $19.1 \%$ of the total forelimb area. In the three lesioned monkeys, the areas of the digit representation were between 55.7 and $64.6 \%$, for the wrist the range was from 20.9 to $24.7 \%$, and for elbow, 14.4 and $20.6 \%$. The differences between the normal monkey and any of the three lesioned monkeys were not significant (NM56 vs LM98, $p=0.500$; NM56 vs LM78, $p=0.250$; and NM56 vs LM01, $p=0.250$; Wilcoxon's test).

\section{Nature of the evoked digit movements}

Monkeys with lesions of the dorsal columns cannot form precision grip using D1 (thumb) and D2 (forefinger), an action that requires coordinated flexion of these two digits (Glendinning et al., 1992). For picking small items, instead of using a precision grip, the monkeys grasp using digits D2 to D5, while securing the grip by adducting D1 (Leonard et al., 1992) (our unpublished observations). We, therefore, compared the nature of the digit movements that are evoked in the normal and the lesioned monkeys (Fig. 7).

The majority of the D1 movements $(94.4 \% ; n=54)$ in the normal monkey NM56 were of flexion-extension type. Adduction-abduction movements were observed at only $5.6 \%$ of the D1 sites (Fig. 7A). However, in the three lesioned monkeys, flexionextension movements were observed at significantly fewer number of sites. In monkey LM98, flexion-extension of D1 was evoked at $45.1 \%$ and adduction-abduction at the remaining $54.9 \%$ of the sites; the difference from the normal monkey was highly significant ( $p<0.0001$, Fisher's exact test). In the lesioned monkey LM78, flexion-extension of D1 was observed at $51.7 \%$ of the sites and adduction-abduction at $48.3 \%$ of the sites, showing a highly significant difference from the normal monkey $(p<$ 0.0001 ; one stimulation site was not considered for this analysis because the nature of the evoked movement was not noted). Finally, in monkey LM01, flexion-extension of D1 was seen at $75.9 \%$ of the D1 movement sites and adduction-abduction at the remaining $24.1 \%$ of the sites, a significant difference from the normal monkey $(p<0.0077)$. The results conform to the known behavioral use of D1 by monkeys with lesions (see Discussion).

Nature of the evoked movement of D2 at all the D2 movement sites is shown in Figure $7 B$. The movements were either flexionextension type or adduction-abduction type. The data show that, in the normal monkey, NM56 flexion-extension of D2 was evoked at $82.5 \%$ of the D2 movement sites $(n=40)$, and adduction-abduction at the remaining $17.5 \%$ of the sites. For the lesioned monkey LM98, flexion-extension of D2 was seen at $94.4 \%$ of the sites $(n=36)$, for monkey LM78 at $100 \%$ of the sites
( $n=34$; at two sites the nature of movement was not noted; therefore, those sites have been excluded from this analyses), and for LM01 at $85 \%$ of the sites $(n=20)$. At the remaining sites, adduction-abduction movements were seen. Although the flexion-extension movements were seen at somewhat larger number of sites for all the lesioned monkeys, the difference was significant only for monkey LM78, which could be attributable to very low number of adduction-abduction sites combined with partial mapping in this monkey as described above (LM98, $p=0.159$; LM78, $p=0.013$; LM01, $p=0.724$; Fisher's exact test). Perhaps the slight increase in the flexion-extension of D2 reflects increased use of the digit with digits D3, D4, and D5 (Cooper et al., 1993).

Interestingly, for the movement type of both D1 and D2 the maximal change was seen in monkeys with complete lesions. Monkey LM01, with partial lesion, showed lesser extent of change compared with the normal monkey. For D1, the movement differences between LM01 and LM98, and LM01 and LM78 were also statistically significant.

\section{Representation of the individual and multiple digit movements}

We determined whether dorsal column lesions and the loss of the ability to make fractionated movements of digits lead to changes in the movement representation in the motor cortex with respect to the number of sites where movements of single digits were evoked at threshold currents.

We considered movements evoked by stimulation in M1 buried in the depths of the anterior bank of the central sulcus for the reasons mentioned above. In all the four monkeys, individual digit movements were observed only for D1, D2, and D5 (Schieber, 1991; Häger-Ross and Schieber, 2000). The most often-evoked individual-digit movement was of D1. Figure 8 shows the number of sites from where movements of D1 alone were evoked as a percentage of all the sites from where D1 movements were evoked. The data show that, for all the four monkeys, at majority of the D1 movement sites, movement of D1 alone was evoked. The movement of D1 in combination with other digits was evoked at $<25 \%$ of the sites. The differences between the lesioned monkeys and the normal monkey were not statistically significant $(\mathrm{LM} 98, p=0.754 ; \mathrm{LM} 78, p=0.581 ; \mathrm{LM} 01, p=0.352$; Fisher's exact test). Movements of D2 or D5 were evoked from 


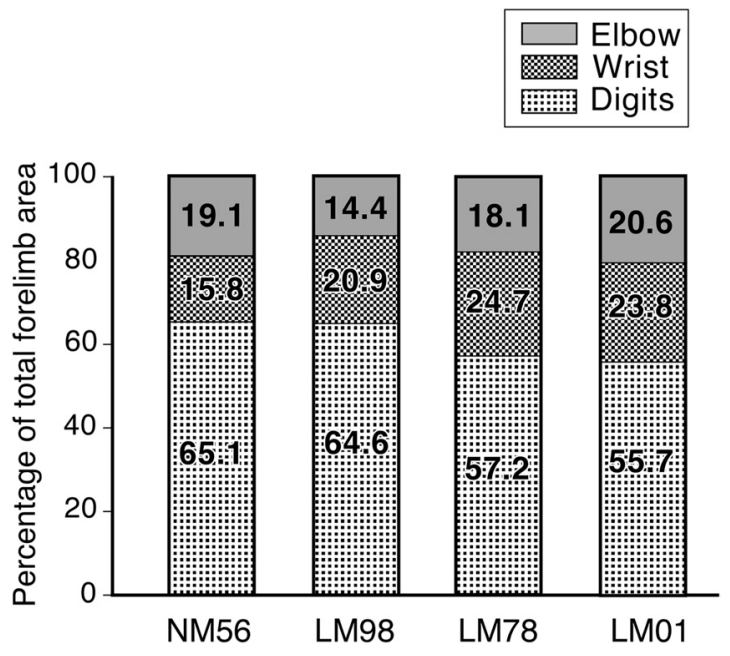

Figure 6. Area of the motor cortex from where movements of the digits, wrist, or elbow were evoked in the normal monkey (NM56) and monkeys with lesions of the dorsal columns (LM98, LM78, and LM01), shown as percentage of the total area of the forelimb movement. The differences between the normal and any of the three lesioned monkeys were not significant.

very few sites and as reported before, the variability between monkeys was high (Schieber, 1991).

\section{Threshold currents required to evoke movements}

We determined whether the threshold currents required to evoke movements of different body parts in the lesioned monkeys are different from those in the normal monkey. Box plots of distribution of threshold currents required to evoke movements of the digits, wrist, elbow, shoulder, and face/tongue for the normal monkey NM56 and the three lesioned monkeys LM98, LM78, and LM01 are shown in Figure 9. Only those stimulation sites that lie in caudal M1 in the rostral bank of the central sulcus were considered for this analysis.

There were no significant differences in the threshold currents between the normal and the lesioned monkeys for movements of the wrist (LM98, $p=0.758 ; \mathrm{LM} 78, p=0.605$; LM01, $p=0.793$; Mann-Whitney rank sum test), shoulder (for LM98, $p=0.289$; LM78, $p=0.518$; LM01, $p=0.582$ ), or face (for LM98, $p=0.153 ; \mathrm{LM} 78, p=0.246 ; \mathrm{LM} 01, p=0.168$ ). The mean threshold current for evoking movements of the digits in the normal monkey NM56 was $15.9 \mu \mathrm{A}$, whereas in the three lesioned monkeys LM98, LM78, and LM01 the currents were higher $(21.8,26.4$, and $22.2 \mu \mathrm{A}$, respectively). The differences between the normal monkey and the lesioned monkey were significant (LM98, $p=0.004 ;$ LM78, $p \leq 0.001 ;$ LM01, $p \leq$ $0.001)$. The mean threshold current required to evoke movements of the elbow in monkey LM98 was also slightly but significantly higher $(p=0.044)$, but the differences between the normal and the other two lesioned monkeys were not significant $(\mathrm{LM} 78, p=0.856 ; \mathrm{LM} 01, p=0.069)$.

\section{Discussion}

The main finding of the present study is that chronic lesions of the dorsal columns at cervical levels in adult monkeys do not cause any change in the overall topography of the movement representation in the motor cortex, although there is a large-scale reorganization in the somatosensory cortex. However, such lesions result in reorganization of the motor cortex such that ICMS evokes flexion-extension of D1 at significantly fewer sites compared with the normal monkeys, with a corresponding increase in
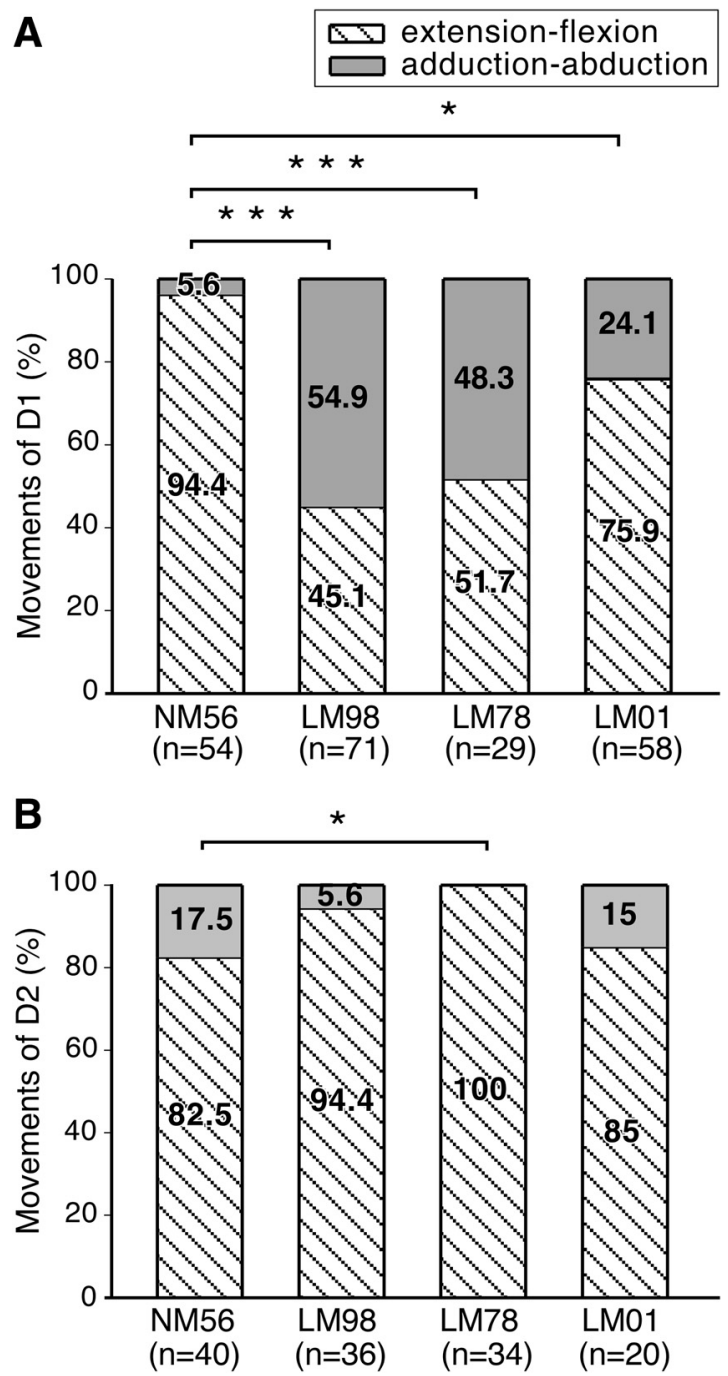

Figure 7. A, Percentage of the stimulation sites from which flexion- extension and adduction-abduction movements of digit 1 were evoked in the normal (NM56) and the lesioned (LM98, LM78, and LM01) monkeys. Adduction-abduction movements are evoked from a larger percentage of sites in monkeys with lesions of the dorsal columns. The differences between the normal monkey and the lesioned monkey were statistically significant. The total number of sites (n) from which D1 movements were evoked is also shown on the abscissa. $\boldsymbol{B}$, Percentage of sites from which flexion- extension and adduction-abduction movements of digit 2 were evoked in the normal and the lesioned monkeys. ${ }^{* *} p<0.001$; ${ }^{*} p<0.05$.

adduction-abduction movements. Threshold currents required to elicit movements of digits were significantly higher in the lesioned monkeys compared with the normal monkey. These changes in the organization of the movement map in monkeys with dorsal column lesions correlate with the behavioral effects of the lesions.

\section{Reorganization of the motor cortex after sensory loss}

As for sensory systems (Merzenich et al., 1983; Kaas et al., 1990, 1997; Gilbert and Wiesel, 1992; Schwaber et al., 1993; Jain, 2002; Tandon et al., 2009), the primary motor cortex of adult mammals undergoes reorganization after neurons lose connections to their targets because of amputation of a limb, motor nerve injury, or a spinal cord injury. In the deefferented cortex, electrical stimulation or transcranial magnetic stimulation evokes movements of the muscles proximal to the site of injury (Sanes et al., 1988, 1990; Levy et al., 1990; Qi et al., 2000). 


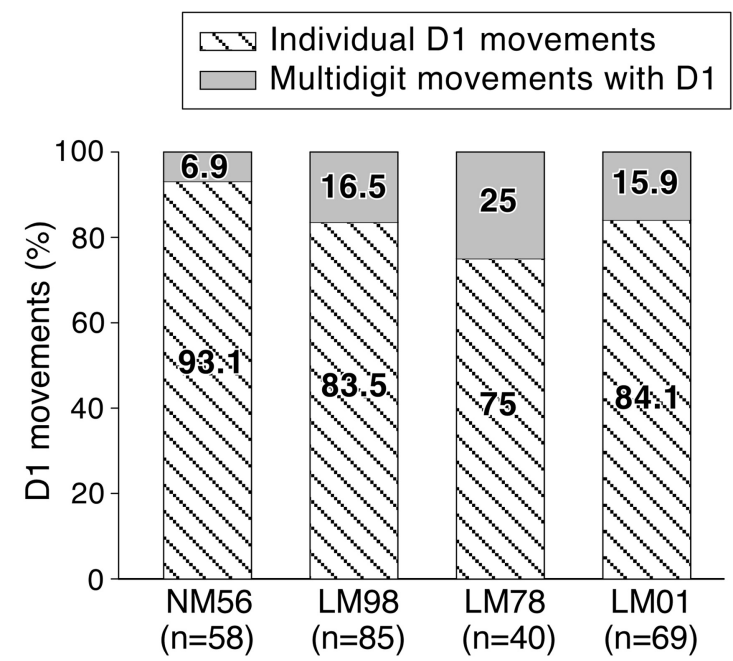

Figure 8. The number of sites from which movements of $\mathrm{D} 1$ alone, or $\mathrm{D} 1$ in combination with other digits were evoked, shown as a percentage of all the sites from where D1 movements were evoked. NM56 is the normal monkey, and LM98, LM78, and LM01 are monkeys with lesions. The total number sites from which D1 movements were evoked, $n$, is shown for each monkey on the abscissa. The differences between the normal monkey and the lesioned monkeys were not significant.

However, studies on the reorganization of the motor cortex after sensory loss are few. According to what are perhaps the earliest reports, transections of the dorsal roots from the limb in adult macaque monkeys did not change the nature and "ease" with which movements of the limbs or digits could be evoked by stimulation of the motor cortex (Mott and Sherrington, 1895; Sherrington, 1931). More recently, Asanuma and Arissian (1984) explored the organization of motor cortex using ICMS in a monkey 2 and $13 \mathrm{~d}$ after a dorsal column lesion. They state that the motor thresholds for eliciting movement were not different from that in control animals. Favorov et al. (1988) also report that there were no changes in the threshold currents for evoking movements from the motor hand area of a monkey with nearly complete bilateral dorsal column lesion. In a second monkey, with unilateral dorsal column lesion, but with involvement of the dorsolateral tracts, the minimum threshold currents were "not much different." The longest recovery period for these monkeys was 2 weeks. These reports do not give details of the movements evoked. Our results confirm these observations to the extent that sensory loss in adult monkeys because of dorsal column lesions does not result in any change in the topography of the motor cortex. Qi et al. (2010) show that if dorsal column lesions are made early in development, before the monkeys are $<12 \mathrm{~d}$ of age, the size of the digit representation in the motor cortex is reduced and the representation becomes fragmented.

We observed a small but significant increase in the threshold currents required for evoking movements in the digit area of the lesioned monkeys, which could be because of long recovery periods for our monkeys. In humans, loss of sensory inputs affects motor cortical excitability and acute sensory nerve block causes changes in the size of the representation of the affected muscle in the motor cortex (Rossini et al., 1996; Rossi et al., 1998; Liepert et al., 2003; Nardone et al., 2008). Lesions of the dorsal columns early in development have been shown to result in an increase in the threshold currents required for evoking movements in addition to affecting organization of the digit area (Qi et al., 2010).

In macaque monkeys, sensory inputs project to the motor cortex via dorsal columns and not spinothalamic pathways
A
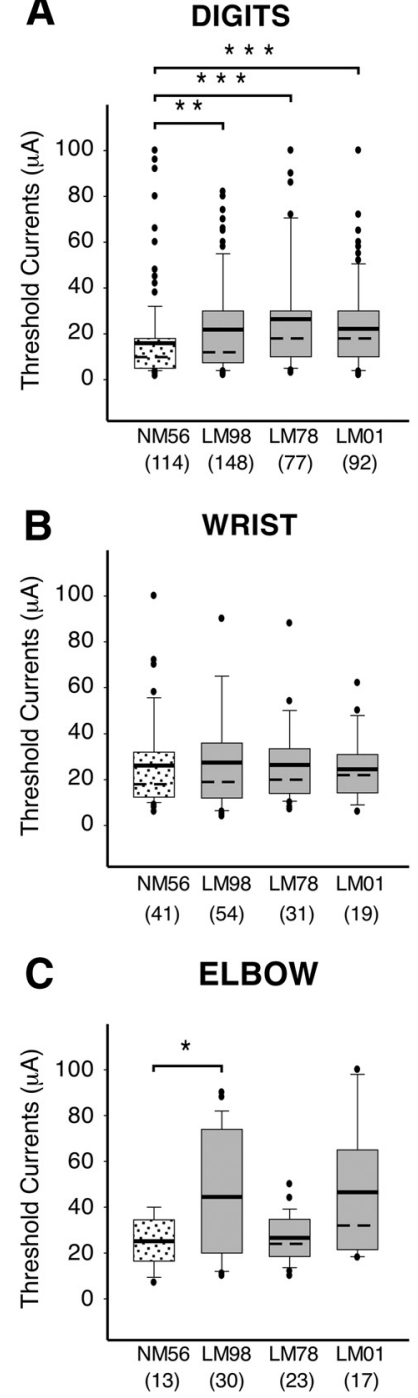

\section{SHOULDER}
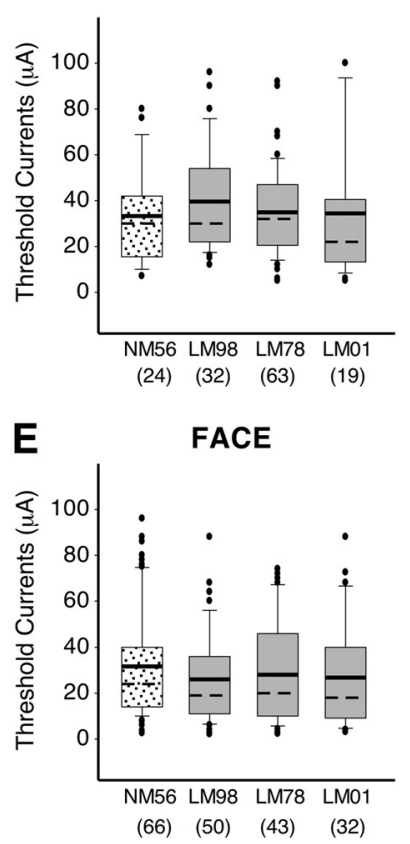

$\mathbf{F}$

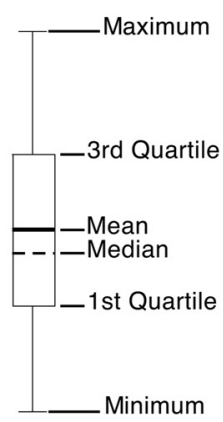

Figure 9. Box plots showing distribution of the threshold currents required to evoke movements of different body parts in the normal (NM56) and the lesioned (LM98, LM78, and LM01) monkeys. The threshold currents for digit movements $(\boldsymbol{A})$ were significantly higher for the lesioned monkeys compared with the normal monkey, whereas the currents required to evoke movements of the wrist, shoulder, and facial muscles $(\boldsymbol{B}, \boldsymbol{D}, \boldsymbol{E})$ were not affected by the lesion. Currents required to evoke movements of the elbow were higher for monkeys LM98, but not for LM78 and LM01 (C). Key to different statistical parameters illustrated in the box plots is shown in $\boldsymbol{F}$. The dots mark the observations that have been deemed to be outliers by the statistical software (SigmaPlot); however, these values were included while calculating the mean and the median. The total number sites from which the movements of each body part were evoked is shown in brackets for each monkey on the abscissa. ${ }^{* * *} p<0.001$; ${ }^{* *} p<0.01 ;{ }^{*} p<0.05$.

(Brinkman et al., 1978; Asanuma et al., 1980). Although initially it was argued that the thalamic motor nucleus, the ventrolateral nucleus, receives direct somatosensory inputs, particularly from deep receptors (Strick, 1976a,b; Asanuma, 1981), subsequent studies ruled out direct projections from the brainstem nuclei, including external cuneate nucleus to the motor thalamic nuclei (Tracey et al., 1980; Kalil, 1981) (see, however, Craig, 2008) (but see Dum et al., 2009). Although we have not determined the somatosensory receptive fields of neurons in the motor cortex of our monkeys, lesions of the dorsal column are likely to deprive the primary motor cortex of its major source of sensory inputs from the hand [Dum et al. (2009) have, however, recently shown an indirect spinothalamic route from cingulate motor areas via the medial dorsal nucleus of the thalamus]. 
Since there are no direct projections from the ventroposterior lateral nucleus to the motor cortex (Strick, 1976a; Ghosh et al., 1987; Matelli et al., 1989; Darian-Smith et al., 1993), the somatosensory cortical inputs are the main afferents to the primary motor cortex. In macaque monkeys, afferents from the somatosensory areas, including areas $3 \mathrm{a}, 1,2,5$, and S2 terminate in M1 in a mostly topographic manner (Jones et al., 1978; Kunzle, 1978; Vogt and Pandya, 1978; Friedman et al., 1986; Pons and Kaas, 1986; Ghosh et al., 1987; Huerta and Pons, 1990; DarianSmith et al., 1993). Because in monkeys with lesions of the dorsal columns somatosensory cortical areas including area 3b, 3a, 1, S2 and PV get reorganized (Jain et al., 1998; Tandon et al., 2009) (N. Jain and J.H. Kaas, unpublished observations), the hand region of the motor cortex will receive abnormal face inputs via the reorganized somatosensory cortex. Our results show that the topography in the motor cortex is not affected by these abnormal sensory inputs.

\section{Altered motor behavior after dorsal column lesions and reorganization of the motor cortex}

We (our unpublished observations) and others (Farrera and Barrera, 1934; Gilman and Denny-Brown, 1966; Leonard et al., 1992; Cooper et al., 1993) have observed that monkeys with lesions of the dorsal columns initially do not use their affected hand for feeding or locomotion, but in $\sim 2$ months they recover most of the use of the hand for locomotion, grasping the cage bars for climbing and using the entire palm and digits for holding large food items. Occasionally, abnormal resting posture of the affected hand persists. However, the monkeys are not able to form precision grip using their thumb and the forefinger, and lose the capacity to make fractionated movements of the digits (Beck, 1976; Eidelberg et al., 1976; Vierck, 1978, 1982; Glendinning et al., 1992; Cooper et al., 1993). They use a palmar grasp to hold small objects.

Loss of precision grip reflects an inability to oppose D1 and D2 by controlled flexion-extension. We have observed that if a food item is presented between D1 and D2 to monkeys with dorsal column lesions, they grasp it by bringing D1 close to D2 by adduction. Leonard et al. (1992) observed similar abnormal digit movements during grooming in monkeys with fasciculus cuneatus lesions. They describe the movement as abnormal scissors grip in which the thumb was adducted against the forefinger-a movement that was never seen preoperatively. Our present results similarly show an increase in evoked D1 adduction-abduction movements and a decrease in flexion-extension.

Although a direct role of abnormal sensory inputs to the motor cortex causing altered pattern of evoked movements in monkeys with lesions cannot be ruled out, it is likely that long-term changes in the behavioral use of the digits result in reorganization of the motor cortex. Use-dependent reorganization of the motor cortex has been seen under a variety of conditions. For example, motor cortex in rats, monkeys, and humans reorganizes after training to learn new motor skills, which require changes in the way joints and muscles are used (Karni et al., 1995; Nudo et al., 1996; Kleim et al., 1998; Tyc et al., 2005; Molina-Luna et al., 2008).

\section{Brain reorganization and altered perception}

Topographic reorganization of the brain has been proposed to underlie abnormal perceptions such as phantom sensations, which are felt by patients after amputations or spinal cord injuries (Sweet, 1975; Ettlin et al., 1980; Katz and Melzack, 1990; Coderre et al., 1993; Ramachandran, 1993; Siddall and McClelland, 1999).
These sensations also have a proprioceptive component. For example, the patients often feel that the phantom is frozen in a particular position and cannot be moved (Katz and Melzack, 1990). We propose that altered sensory and proprioceptive inputs are an important component of these abnormal sensations and the mental inability to move the phantom. The argument is supported by our results showing normal organization of the motor cortex, indicating that such problems do not stem from lack of any motor ability. Furthermore, if the missing sensory inputs are replaced by illusory visual inputs, the patient is able to mentally manipulate the phantom (Ramachandran and Altschuler, 2009). Visual feedback perhaps also underlies recovery of gross behaviors in the use of the affected hand after dorsal column injuries (Cole and Glees, 1953; Brochier et al., 1999).

\section{References}

Asanuma H (1981) Functional role of sensory inputs to the motor cortex. Prog Neurobiol 16:241-262.

Asanuma H, Arissian K (1984) Experiments on functional role of peripheral input to motor cortex during voluntary movements in the monkey. J Neurophysiol 52:212-227.

Asanuma H, Arnold AP (1975) Noxious effects of excessive currents used for intracortical microstimulation. Brain Res 96:103-107.

Asanuma H, Larsen K, Yumiya H (1980) Peripheral input pathways to the monkey motor cortex. Exp Brain Res 38:349-355.

Beck C (1976) Forelimb performance by squirrel monkeys (Saimiri sciureus) before and after dorsal column lesions. J Comp Physiol Psychol 90:353-362.

Brinkman J, Bush BM, Porter R (1978) Deficient influence of peripheral stimuli on precentral neurones in monkeys with dorsal column lesions. J Physiol 276:27-48.

Brochier T, Boudreau MJ, Paré M, Smith AM (1999) The effects of muscimol inactivation of small regions of motor and somatosensory cortex on independent finger movements and force control in the precision grip. Exp Brain Res 128:31-40.

Coderre TJ, Katz J, Vaccarino AL, Melzack R (1993) Contribution of central neuroplasticity to pathological pain: review of clinical and experimental evidence. Pain 52:259-285.

Cole J, Glees P (1953) Tests used in the localization of cerebral function in trained monkeys. Experientia 9:268-271.

Cooper BY, Glendinning DS, Vierck CJ Jr (1993) Finger movement deficits in the stumptail macaque following lesions of the fasciculus cuneatus. Somatosens Mot Res 10:17-29.

Craig AD (2008) Retrograde analyses of spinothalamic projections in the macaque monkey: input to the ventral lateral nucleus. J Comp Neurol 508:315-328.

Darian-Smith C, Ciferri MM (2005) Loss and recovery of voluntary hand movements in the macaque following a cervical dorsal rhizotomy. J Comp Neurol 491:27-45.

Darian-Smith C, Darian-Smith I, Burman K, Ratcliffe N (1993) Ipsilateral cortical projections to areas $3 \mathrm{a}, 3 \mathrm{~b}$, and 4 in the macaque monkey. J Comp Neurol 335:200-213.

Dum RP, Levinthal DJ, Strick PL (2009) The spinothalamic system targets motor and sensory areas in the cerebral cortex of monkeys. J Neurosci 29:14223-14235.

Eidelberg E, Woolf B, Kreinick CJ, Davis F (1976) Role of the dorsal funiculi in movement control. Brain Res 114:427-438.

Ettlin TM, Seiler W, Kaeser HE (1980) Phantom and amputation illusions in paraplegic patients. Eur Neurol 19:12-19.

Farrera A, Barrera SE (1934) Effects of experimental lesions of the posterior columns in macacus rhesus monkey. Brain 57:307-332.

Favorov O, Sakamoto T, Asanuma H (1988) Functional role of corticoperipheral loop circuits during voluntary movements in the monkey: a preferential bias theory. J Neurosci 8:3266-3277.

Florence SL, Wall JT, Kaas JH (1988) The somatotopic pattern of afferent projections from the digits to the spinal cord and cuneate nucleus in macaque monkeys. Brain Res 452:388-392.

Florence SL, Wall JT, Kaas JH (1989) Somatotopic organization of inputs from the hand to the spinal gray and cuneate nucleus of monkeys with observations on the cuneate nucleus of humans. J Comp Neurol 286:48-70. 
Friedman DP, Murray EA, O’Neill JB, Mishkin M (1986) Cortical connections of the somatosensory fields of the lateral sulcus of macaques: evidence for a corticolimbic pathway for touch. J Comp Neurol 252: 323-347.

Geneser-Jensen FA, Blackstad TW (1971) Distribution of acetyl cholinesterase in the hippocampal region of the guinea pig. I. Entorhinal area, parasubiculum, and presubiculum. Z Zellforsch Mikrosk Anat 114:460-481.

Gentilucci M, Toni I, Daprati E, Gangitano M (1997) Tactile input of the hand and the control of reaching to grasp movements. Exp Brain Res 114:130-137.

Geyer S, Matelli M, Luppino G, Zilles K (2000) Functional neuroanatomy of the primate isocortical motor system. Anat Embryol (Berl) 202:443-474.

Ghosh S, Brinkman C, Porter R (1987) A quantitative study of the distribution of neurons projecting to the precentral motor cortex in the monkey (M. fascicularis). J Comp Neurol 259:424-444.

Gilbert CD, Wiesel TN (1992) Receptive field dynamics in adult primary visual cortex. Nature 356:150-152.

Gilman S, Denny-Brown D (1966) Disorders of movement and behaviour following dorsal column lesions. Brain 89:397-418.

Glendinning DS, Cooper BY, Vierck CJ Jr, Leonard CM (1992) Altered precision grasping in stumptail macaques after fasciculus cuneatus lesions. Somatosens Mot Res 9:61-73.

Godschalk M, Mitz AR, van Duin B, van der Burg H (1995) Somatotopy of monkey premotor cortex examined with microstimulation. Neurosci Res 23:269-279.

Häger-Ross C, Schieber MH (2000) Quantifying the independence of human finger movements: comparisons of digits, hands, and movement frequencies. J Neurosci 20:8542-8550.

Hikosaka O, Tanaka M, Sakamoto M, Iwamura Y (1985) Deficits in manipulative behaviors induced by local injections of muscimol in the first somatosensory cortex of the conscious monkey. Brain Res 325:375-380.

Huerta MF, Pons TP (1990) Primary motor cortex receives input from area $3 \mathrm{a}$ in macaques. Brain Res 537:367-371.

Jain N (2002) Adult brain plasticity-what is revealed is exciting, what is hidden is critical. J Biosci 27:439-442.

Jain N, Catania KC, Kaas JH (1997) Deactivation and reactivation of somatosensory cortex after dorsal spinal cord injury. Nature 386:495-498.

Jain N, Catania KC, Kaas JH (1998) A histologically visible representation of the fingers and palm in primate area $3 \mathrm{~b}$ and its immutability following long-term deafferentations. Cereb Cortex 8:227-236.

Jain N, Florence SL, Qi HX, Kaas JH (2000) Growth of new brainstem connections in adult monkeys with massive sensory loss. Proc Natl Acad Sci U S A 97:5546-5550.

Jain N, Qi HX, Collins CE, Kaas JH (2008) Large-scale reorganization in the somatosensory cortex and thalamus after sensory loss in macaque monkeys. J Neurosci 28:11042-11060.

Jones EG, Coulter JD, Hendry SH (1978) Intracortical connectivity of architectonic fields in the somatic sensory, motor and parietal cortex of monkeys. J Comp Neurol 181:291-347.

Kaas JH, Krubitzer LA, Chino YM, Langston AL, Polley EH, Blair N (1990) Reorganization of retinotopic cortical maps in adult mammals after lesions of the retina. Science 248:229-231.

Kaas JH, Florence SL, Jain N (1997) Reorganization of sensory systems of primates after injury. Neuroscientist 3:123-129.

Kalil K (1981) Projections of the cerebellar and dorsal column nuclei upon the thalamus of the rhesus monkey. J Comp Neurol 195:25-50.

Karni A, Meyer G, Jezzard P, Adams MM, Turner R, Ungerleider LG (1995) Functional MRI evidence for adult motor cortex plasticity during motor skill learning. Nature 377:155-158.

Katz J, Melzack R (1990) Pain "memories" in phantom limbs: review and clinical observations. Pain 43:319-336.

Kleim JA, Barbay S, Nudo RJ (1998) Functional reorganization of the rat motor cortex following motor skill learning. J Neurophysiol 80:3321-3325.

Kunzle (1978) Cortico-cortical efferents of primary motor and somatosensory regions of the cerebral cortex in Macaca fascicularis. Neuroscience 3:25-39.

Kwan HC, MacKay WA, Murphy JT, Wong YC (1978) Spatial organization of precentral cortex in awake primates. II. Motor outputs. J Neurophysiol 41:1120-1131.

Leonard CM, Glendinning DS, Wilfong T, Cooper BY, Vierck CJ Jr (1992)
Alterations of natural hand movements after interruption of fasciculus cuneatus in the macaque. Somatosens Mot Res 9:75-89.

Levy WJ Jr, Amassian VE, Traad M, Cadwell J (1990) Focal magnetic coil stimulation reveals motor cortical system reorganized in humans after traumatic quadriplegia. Brain Res 510:130-134.

Liepert J, Gorsler A, van Eimeren T, Münchau A, Weiller C (2003) Motor excitability in a patient with a somatosensory cortex lesion. Clin Neurophysiol 114:1003-1008.

Matelli M, Luppino G, Fogassi L, Rizzolatti G (1989) Thalamic input to inferior area 6 and area 4 in the macaque monkey. J Comp Neurol 280:468-488

Merzenich MM, Kaas JH, Wall J, Nelson RJ, Sur M, Felleman D (1983) Topographic reorganization of somatosensory cortical areas $3 \mathrm{~b}$ and 1 in adult monkeys following restricted deafferentation. Neuroscience 8:33-55.

Molina-Luna K, Hertler B, Buitrago MM, Luft AR (2008) Motor learning transiently changes cortical somatotopy. Neuroimage 40:1748-1754.

Mott FW, Sherrington CS (1895) Experiments upon the influence of sensory neurons upon movement and nutrition of limbs. Preliminary communication. Proc R Soc Lond 57:481-488.

Nardone R, Golaszewski S, Bergmann J, Venturi A, Prünster I, Bratti A, Ladurner G, Tezzon F (2008) Motor cortex excitability changes following a lesion in the posterior columns of the cervical spinal cord. Neurosci Lett 434:119-123.

Nathan PW, Sears TA (1960) Effects of posterior root section on the activity of some muscles in man. J Neurol Neurosurg Psychiatry 23:10-22.

Nudo RJ, Milliken GW, Jenkins WM, Merzenich MM (1996) Usedependent alterations of movement representations in primary motor cortex of adult squirrel monkeys. J Neurosci 16:785-807.

Osborne LC, Lisberger SG, Bialek W (2005) A sensory source for motor variation. Nature 437:412-416

Park MC, Belhaj-Saif A, Gordon M, Cheney PD (2001) Consistent features in the forelimb representation of primary motor cortex in rhesus macaques. J Neurosci 21:2784-2792.

Pavlides C, Miyashita E, Asanuma H (1993) Projection from the sensory to the motor cortex is important in learning motor skills in the monkey. J Neurophysiol 70:733-741.

Pearce AJ, Thickbroom GW, Byrnes ML, Mastaglia FL (2000) Functional reorganisation of the corticomotor projection to the hand in skilled racquet players. Exp Brain Res 130:238-243.

Pons TP, Kaas JH (1986) Corticocortical connections of area 2 of somatosensory cortex in macaque monkeys: a correlative anatomical and electrophysiological study. J Comp Neurol 248:313-335.

Preuss TM, Stepniewska I, Jain N, Kaas JH (1997) Multiple divisions of macaque precentral motor cortex identified with neurofilament antibody SMI-32. Brain Res 767:148-153.

Qi HX, Stepniewska I, Kaas JH (2000) Reorganization of primary motor cortex in adult macaque monkeys with long-standing amputations. J Neurophysiol 84:2133-2147.

Qi HX, Jain N, Collins CE, Lyon DC, Kaas JH (2010) Functional organization of motor cortex of adult macaque monkeys is altered by sensory loss in infancy. Proc Natl Acad Sci U S A 107:3192-3197.

Ramachandran VS (1993) Behavioral and magnetoencephalographic correlates of plasticity in the adult human brain. Proc Natl Acad Sci U S A 90:10413-10420.

Ramachandran VS, Altschuler EL (2009) The use of visual feedback, in particular mirror visual feedback, in restoring brain function. Brain 132:1693-1710.

Raos V, Franchi G, Gallese V, Fogassi L (2003) Somatotopic organization of the lateral part of area F2 (dorsal premotor cortex) of the macaque monkey. J Neurophysiol 89:1503-1518.

Rathelot JA, Strick PL (2006) Muscle representation in the macaque motor cortex: an anatomical perspective. Proc Natl Acad Sci USA 103:8257-8262.

Rathelot JA, Strick PL (2009) Subdivisions of primary motor cortex based on cortico-motoneuronal cells. Proc Natl Acad Sci U S A 106:918-923.

Rossi S, Pasqualetti P, Tecchio F, Sabato A, Rossini PM (1998) Modulation of corticospinal output to human hand muscles following deprivation of sensory feedback. Neuroimage 8:163-175.

Rossini PM, Rossi S, Tecchio F, Pasqualetti P, Finazzi-Agrò A, Sabato A (1996) Focal brain stimulation in healthy humans: motor maps changes following partial hand sensory deprivation. Neurosci Lett 214:191-195. 
Rothwell JC, Traub MM, Day BL, Obeso JA, Thomas PK, Marsden CD (1982) Manual motor performance in a deafferented man. Brain 105:515-542.

Sanes JN, Donoghue JP (1992) Organization and adaptability of muscle representations in primary motor cortex. In: Control of arm movement in space: neurophysiological and computational approaches (Caminiti R, Johnson PB, Burnod Y, eds), pp 103-127. Berlin: Springer.

Sanes JN, Mauritz KH, Evarts EV, Dalakas MC, Chu A (1984) Motor deficits in patients with large-fiber sensory neuropathy. Proc Natl Acad Sci U S A 81:979-982.

Sanes JN, Suner S, Lando JF, Donoghue JP (1988) Rapid reorganization of adult rat motor cortex somatic representation patterns after motor nerve injury. Proc Natl Acad Sci U S A 85:2003-2007.

Sanes JN, Suner S, Donoghue JP (1990) Dynamic organization of primary motor cortex output to target muscles in adult rats. I. Long-term patterns of reorganization following motor or mixed peripheral nerve lesions. Exp Brain Res 79:479-491.

Schieber MH (1991) Individuated finger movements of rhesus monkeys: a means of quantifying the independence of the digits. J Neurophysiol 65:1381-1391.

Schwaber MK, Garraghty PE, Kaas JH (1993) Neuroplasticity of the adult primate auditory cortex following cochlear hearing loss. Am J Otol 14:252-258.

Sessle BJ, Wiesendanger M (1982) Structural and functional definition of the motor cortex in the monkey (Macaca fascicularis). J Physiol 323:245-265.

Sherrington CS (1931) Quantitative management of contraction in lowest level co-ordination. Hughlings Jackson Lecture. Brain 54:1-28.

Siddall PJ, McClelland J (1999) Non-painful sensory phenomena after spinal cord injury. J Neurol Neurosurg Psychiatry 66:617-622.

Stepniewska I, Preuss TM, Kaas JH (1993) Architectonics, somatotopic organization, and ipsilateral cortical connections of the primary motor area (M1) of owl monkeys. J Comp Neurol 330:238-271.
Strick PL (1976a) Anatomical analysis of ventrolateral thalamic input to primate motor cortex. J Neurophysiol 39:1020-1031.

Strick PL (1976b) Activity of ventrolateral thalamic neurons during arm movement. J Neurophysiol 39:1032-1044.

Strick PL, Preston JB (1978) Multiple representation in the primate motor cortex. Brain Res 154:366-370.

Sweet WH (1975) "Phantom" sensations following intraspinal injury. Neurochirurgia (Stuttg) 18:139-154.

Tandon S, Kambi N, Jain N (2008) Overlapping representations of the neck and whiskers in the rat motor cortex revealed by mapping at different anaesthetic depths. Eur J Neurosci 27:228-237.

Tandon S, Kambi N, Lazar L, Mohammed H, Jain N (2009) Large-scale expansion of the face representation in somatosensory areas of the lateral sulcus after spinal cord injuries in monkeys. J Neurosci 29:12009-12019.

Tracey DJ, Asanuma C, Jones EG, Porter R (1980) Thalamic relay to motor cortex: afferent pathways from brain stem, cerebellum, and spinal cord in monkeys. J Neurophysiol 44:532-554.

Tyc F, Boyadjian A, Devanne H (2005) Motor cortex plasticity induced by extensive training revealed by transcranial magnetic stimulation in human. Eur J Neurosci 21:259-266.

Vierck CJ Jr (1978) Comparison of forelimb and hindlimb motor deficits following dorsal column section in monkeys. Brain Res 146:279-294.

Vierck CJ Jr (1982) Comparison of the effects of dorsal rhizotomy or dorsal column transection on motor performance of monkeys. Exp Neurol 75:566-575.

Vogt BA, Pandya DN (1978) Cortico-cortical connections of somatic sensory cortex (areas 3,1 and 2) in the rhesus monkey. J Comp Neurol 177:179-191.

Wong-Riley M (1979) Changes in the visual system of monocularly sutured or enucleated cats demonstrable with cytochrome oxidase histochemistry. Brain Res 171:11-28. 